\title{
A POLÍTICA DA POLÍTICA EXTERNA BRASILEIRA: NOVAMENTE ENTRE AUTONOMIA E ALINHAMENTO NA ELEIÇÃO DE 2014
}

\section{The politics of Brazilian foreign policy: again between autonomy and alignment in election 2014}

\author{
Diego Pautasso ${ }^{1}$ \\ Gabriel Pessin Adam ${ }^{2}$
}

\section{Introdução}

A eleição presidencial de 2014 se avizinha e, naturalmente, coloca em discussão as opções políticas acerca do desenvolvimento nacional e da inserção internacional do País. O presente artigo busca incrementar o debate sobre a política externa brasileira a partir das visões manifestadas por alguns dos candidatos à Presidência e por intelectuais ligados a eles. E aqui cabe uma clarificação conceitual: embora seja uma política de Estado, com necessários traços de continuidade, esta é uma política e, portanto, deve refletir as opções de cada governo. E, como destaca Faria (2012), a redemocratização do País e as mudanças sistêmicas têm pressionado o Itamaraty no sentido da superação do insulamento burocrático ${ }^{3}$. Atualmente isso se reflete no maior ativismo do Congresso no assunto, no maior envolvimento do País na economia internacional e na liderança brasileira diante de conflitos regionais, combinado com a erosão da coesão diplomática

\footnotetext{
${ }^{1}$ Doutor e mestre em Ciência Política e graduado em Geografia pela UFRGS. Atualmente é professor de Relações Internacionais da ESPM Sul e da UNISINOS. Autor do livro China e Rússia no Pós-Guerra Fria, ed. Juruá, 2011. E-mail: dgpautasso@gmail.com

${ }^{2}$ Doutor Ciência Política e mestre em Relações Internacionais pela UFRGS e graduado em Ciência Jurídicas pela PUC-RS. Atualmente é professor de Relações Internacionais da ESPM Sul e da UNISINOS. E-mail: gabriel.pessin@gmail.com

${ }^{3}$ Segundo Faria, (2012), o insulamento decorre de inúmeros fatores, entre eles: grande autonomia do Executivo na formulação da política externa; o modelo de substituição de importações ter sido bem sucedido e gerado introversões; o caráter pouco conflitivo da diplomacia brasileira; da profissionalização do corpo diplomático (combinado com a pequena atuação de profissionais externos atuando no MRE); e do baixo montante orçamentário do Ministério.
} 


\section{Conjuntura Austral}

visível pela atuação militante de diplomatas aposentados na grande mídia. Com efeito, a política externa tem dependido de maior coordenação intragovernamental (Executivo) e intergovernamental (entre unidades da federação), bem como de cooperação intersetorial com atores societários. A inclusão de adidos agrícolas nas embaixadas, o ativismo das unidades subnacionais, a intensificação do papel do MRE na opinião pública - através d ecanal no Youtube, de publicações da FUNAG e da divulgação na mídia impressa (FARIA, 2012, p. 320)- e a forte interação com a academia ${ }^{4}$ são alguns exemplos desse cenário mais complexo na formulação da política externa.

Na medida em que vem ocorrendo o des-insulamento da formulação da política externa, progressivamente este tema ganha a opinião pública e, por isso, passa a repercutir os interesses das diversas forças político-partidárias, as quais, por seu turno, no mais das vezes representam determinados grupos socioeconômicos. Nesse sentido, afirmar que há uma política a conduzir a política externa significa admitir que sua formulação cabe ao Executivo por atribuição legal, a partir dos partidos que compõem a coalizão de governo,submetidas as outras esferas com atribuições legais (Congresso) e, em razão do des-insulamento, em diálogo com os demais participantes nas esferas governamentais e sociais. Ao Itamaraty, pois, resta a complexa tarefa de implementar, a partir de seu corpo de funcionário especializados, as diretrizes da política externa.

O presente artigo parte do pressuposto que a história da política externa brasileira tem sido historicamente orientada por dois modelos principais. De um lado, um modelo que prega o alinhamento com os polos centrais do sistema internacional sobretudo os Estados Unidos, em função de condições histórias, econômicas e geográficas - como melhor alternativa para o desenvolvimento do Brasil. O modelo alternativo sustenta a necessidade de o país buscar maior autonomia em relação aos polos centrais de poder como forma de defender os interesses brasileiros na arena internacional, com o intuito último de melhorar as condições internas do país. Por certo, tais categorias nem sempre são estanques, pois fatores internos e a dinâmica da política

\footnotetext{
${ }^{4}$ Como o evento Diálogos de Política Externa: em debate entre Governo e Sociedade sobre o papel do Brasil no mundo. Disponível em: http://diplomaciapublica.itamaraty.gov.br/itamaraty/60-dialogos-sobrepolitica-externa-um-debate-entre-governo-e-sociedade-sobre-o-papel-do-brasil-no-mundo. Acesso em $18 / 06 / 2014$.
} 


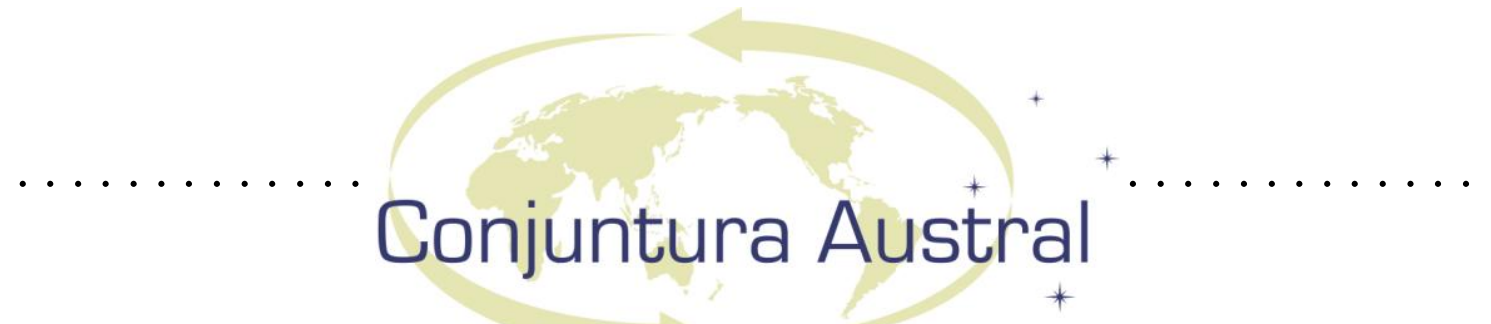

internacional fazem com que alguns governos defensores do alinhamento não o adotem cega ou incondicionalmente, bem como obrigam a governos autonomistas a desenvolverem políticas menos ousadas em suas linhas de ação.Não é necessário retroagir muito no passado da política externa brasileira para encontrar exemplos de uma e outra linhagem.

Dito isto, o objetivo central do presente artigo consiste na análise dos rumos que a política externa brasileira poderá tomar nos próximos quatro anos (ao menos), tendo em vista os posicionamentos externados pelos candidatos à Presidência relacionados com temas de política internacional, bem como as forças político-partidárias que os representam. Por um lado, pode haver a continuidade da política externa desenvolvida no Governo Lula (2003-2006) e continuada no Governo Dilma (2011-2014). A campanha que representa a manutenção do paradigma atual é a coligação Com a Força do Povo, cuja candidata é a atual Presidenta Dilma Rousseff, do Partido dos Trabalhadores (PT). Por outro, os projetos concorrentes criticam o atual governo de perspectivas opostas. Um deles se aproxima do paradigma do alinhamento, representados tanto pela coalizão Muda Brasil, encabeçada por Aécio Neves, do Partido da Social Democracia Brasileira (PSDB) ${ }^{5}$, e pela coalizão Unidos Pelo Brasil, representada por Marina Silva (após a fatídica morte do presidenciável Eduardo Campos), filiado ao Partido Socialista Brasileiro ${ }^{6}$. A outra se baseia numa perspectiva esquerdista, tendo como representante a candidata Luciana Genro, do Partido Socialismo e Liberdade (PSOL) ${ }^{7}$.

A fim de atingir as metas propostas, o artigo dividido em quatro seções. A primeira abordará as linhas gerais da política externa brasileira dos Governos Lula e

\footnotetext{
${ }^{5}$ A escolha de Aécio Neves como exemplo da corrente de alinhamento na política externa se justifica em função de o PSDB ser o partido do Presidente Fernando Henrique Cardoso (1995-2002), e de ter sido o desafiante do PT no segundo turno das últimas três eleições presidenciais. Ademais, a coligação Muda Brasil possui 92 cadeiras na Câmara dos Deputados e 23 no Senado Federal.

6 As candidaturas de Eduardo Campos e agora de Marina Silva surgiram de defecções do bloco governista. A (re)construção de suas identidades políticas oposicionistas têm feito caminhos divergentes entre si.

${ }^{7}$ Dentre os candidatos à Presidência que poderiam representar a corrente política mais à esquerda do Governo - Luciana Genro, Mauro Iasi (PCB), Rui Costa Pimenta (PCO) e Zé Maria (PSTU) - a escolha por Luciana Genro é justificada em função de seu partido ser o único dentre os acima referidos a possuir cadeiras (3) na Câmara dos Deputados e uma no Senado Federal.
} 


\section{Conjuntura Austral}

Dilma. A segunda apresentará as concepções de política externa manifestadas até então pelas duas principais correntes oposicionistas, acima mencionadas. Após, será realizada análise acerca dos caminhos identificados para a política externa brasileira a partir das candidaturas apresentadas. O encerramento, então, se dará nas considerações finais.

\section{Os governos Lula e Dilma: autonomismo com diferenças}

O resgate da política externa do Governo Lula é fundamental para o esforço empreendido no presente artigo, tendo em vista a continuidade de suas linhas gerais no Governo Dilma, o que provavelmente ocorrerá em caso de reeleição da Presidenta. Tal retomada deve levar em consideração o fato de que a política externa talvez seja uma das facetas mais estudadas do Governo Lula, sobretudo em função de suas inegáveis conquistas e avanços em direção a um maior protagonismo do Brasil no sistema internacional.

Ao analisarmos discursos emblemáticos de Lula e Dilma voltados para aos temas internacionais, observa-se a consonância entre os discursos e as práticas adotadas posteriormente. Já no discurso de posse de Luiz Inácio Lula da Silva, era possível visualizar as linhas gerais do que veio a ser a política externa do seu governo. Ainda que em várias oportunidades os pronunciamentos inaugurais de governo não correspondam à prática subsequente, nesse caso a consonância foi acentuada. A América do Sul receberia destaque na política externa do país.

A grande prioridade da política externa durante o meu Governo será a construção de uma América do Sul politicamente estável, próspera e unida, com base em ideais democráticos e de justiça social. Para isso é essencial uma ação decidida de revitalização do MERCOSUL, enfraquecido pelas crises de cada um de seus membros e por visões muitas vezes estreitas e egoístas do significado da integração (SILVA, 2003).

Além da América do Sul, parceiros tradicionais como Estados Unidos, União Europeia e seus Estados-membros e Japão foram citados, denominados de países desenvolvidos. Ao lado destes, o Brasil aprofundaria relações com as grandes nações 


\section{Conjuntura Austral}

em desenvolvimento, ou seja, Rússia, China, Índia e África do Sul, as quais, juntamente com o Brasil, formam os BRICS. Ressalte-se que à época, ainda não havia sido realizado nenhum encontro formal de alto nível dos BRICS, o que ocorreu apenas em 2009. No tocante à África, bastante negligenciada na Era FHC, o Brasil trabalharia para reafirmar os laços profundos que uniam o País a todo o continente africano, dotado de enormes potencialidades a serem desenvolvidas (SILVA, 2003).

A divisão entre países industrializados e nações em desenvolvimentos indicava a leitura acerca dos rumos desenhados para o sistema internacional, um deles aferrado ao unilateralismo estadunidense, ladeado e alardeado por seus parceiros costumeiros e outro que sinalizava uma multipolaridade menos impositiva e mais solidária. Especificamente acerca desse tema, assim se posicionou o Presidente Lula em seu discurso:

Visamos não só a explorar os benefícios potenciais de um maior intercâmbio econômico e de uma presença maior do Brasil no mercado internacional, mas também a estimular os incipientes elementos de multipolaridade da vida internacional contemporânea.

A democratização das relações internacionais sem hegemonias de qualquer espécie é tão importante para o futuro da humanidade quanto a consolidação e o desenvolvimento da democracia no interior de cada Estado. Vamos valorizar as organizações multilaterais, em especial as Nações Unidas, a quem cabe a primazia na preservação da paz e da segurança internacionais. As resoluções do Conselho de Segurança devem ser fielmente cumpridas. Crises internacionais como a do Oriente Médio devem ser resolvidas por meios pacíficos e pela negociação. Defenderemos um Conselho de Segurança reformado, representativo da realidade contemporânea com países desenvolvidos e em desenvolvimento das várias regiões do mundo entre os seus membros permanentes (SILVA, 2003).

As linhas gerais expostas no discurso de posse foram aprofundadas, incrementadas, debatidas, difundidas e aplicadas pelas esferas de poder responsáveis pelo esteio e pela realização da política externa brasileira, quais sejam o Poder Executivo, na figura ativa do próprio Presidente, o Itamaraty, liderado pelo 


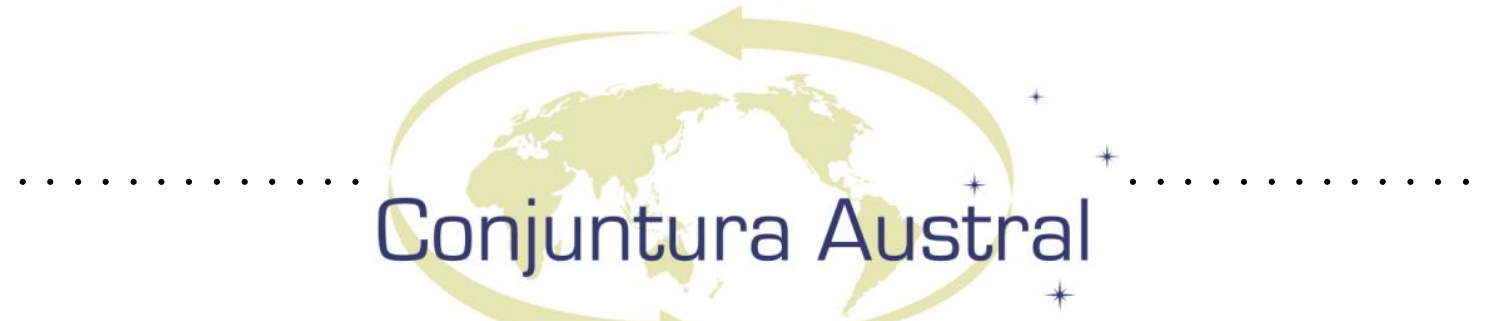

protagonismo do Chanceler Celso Amorim, e a base político-partidária, cuja formulação coube, em grande medida, ao professor Marco Aurélio Garcia, quadro histórico do PT.

Um dos traços mais distintivos da política externa brasileira na primeira década do século XXI foi o fortalecimento de relações com países, regiões e continentes que não faziam parte da paisagem internacional vislumbrada pelo Governo FHC. Talvez o símbolo mais fulgurante destas iniciativas tenha sido o avanço sem precedentes na África. É verdade que nos Governos Jânio/Jango e Geisel o continente africano foi tratado com atenção por Brasília, mas o contingente de viagens, investimentos, parceiras, projetos conjuntos e abertura de embaixadas verificado no Governo Lula foram inéditos, em termos quantitativos e qualitativos.

O foco nos países emergentes também foi uma característica marcada desta política externa. Nesse contexto, no ano de 2009, a China se tornou o principal parceiro econômico do Brasil (com trocas comerciais saltando de 4 bilhões de 2002 para mais de 83,3 bilhões de dólares) ${ }^{8}$. Para além dos fatores comerciais, a parceria estratégica estabelecida em 1993 gerou em 2006 o COSBAN (Comissão Sino-Brasileira de Alto Nível de Concertação e Cooperação), e foi alçada à condição de parceria estratégica global em 2012, já no Governo Dilma. Ao longo do Governo Lula o Brasil também estabeleceu parcerias estratégicas com a Índia (2006), com a Rússia (2008) e com a África do Sul (2010). A concretização dessas alianças estratégicas tornou as cúpulas dos BRICS, realizadas anualmente desde 2009, uma progressão natural dos contatos bilaterais estabelecidos entre as cinco potências emergentes. AVI Cúpula dos BRICS, mais do que o importante anúncio da criação do Novo Banco de Desenvolvimento e do Arranjo Continente de Reservas, sinaliza que esta coalizão está forjando pressões e ações para alterar a distribuição de poder no mundo e as formas de governança. ${ }^{9}$

O Oriente Médio não escapou do radar brasileiro, em que pese a invasão estadunidense ao Iraque em 2003 ter afastado Brasília de seu principal parceiro árabe.

\footnotetext{
${ }^{8}$ Incluindo Hong Kong, pode-se acrescer mais 4 bilhões de dólares - curiosamente, quase o comércio que o Brasil tinha com a RPC há uma década. Dados oficiais do Ministério do Desenvolvimento, Indústria e Comércio. Disponível em http://www.desenvolvimento.gov.br/sitio/interna/interna.php?area=5\&menu=576

9 A Declaração de Fortaleza está disponível em: http://www.itamaraty.gov.br/sala-de-imprensa/notas-aimprensa/vi-cupula-brics-declaracao-de-fortaleza
} 


\section{Conjuntura Austral}

Ainda no seu primeiro ano de mandato, Lula visitou cinco países (Egito, Emirados Árabes, Líbano, Líbia e Síria). Em 2005, ocorreu a primeira Cúpula América do SulPaíses Árabes (CASPA). Ademais, o Brasil não e furtou de agir nos temas mais controversos daquela região. No conflito Israel-Palestina, o país manteve sua histórica posição de defesa de dois Estados, nesse sentido abriu um escritório de representação comercial na Palestina em 2004 e defendeu que o assunto seja efetivamente debatido no Conselho de Segurança, bem como propugnou um maior número de negociadores para tentar solucionar um dos maiores focos de instabilidade global (GARCIA, 2011). Resultado de seus esforços, o Brasil foi convidado para a Conferência de Paz de Annapolis de 2007. Outro tema impactante do Oriente Médio no qual Brasil procurou protagonismo como negociador internacional é o programa nuclear iraniano. No ano de 2010, juntamente com a Turquia, o Brasil conseguiu chegar a bom termo com o governo iraniano, emitindo a Declaração de Teerã, documento em que o Irã acordava com inspeções externas nas suas instalações nucleares. Contudo, a solução, reconhecidamente positiva para a comunidade internacional, foi boicotada pelos Estados Unidos e potências europeias, razão pela qual não foi implementada.

O ampliar do leque da diplomacia brasileira do Governo Lula passou a ser representou o fortalecimento das relações sul-sul, estratégia denominada de autonomia pela diversificação por Cepaluni e Vigevani (2007). Cumpre salientar que não houve o abandono do eixo Norte por parte do Brasil. Como destacado no discurso de Lula, Estados Unidos, Japão e União Europeia continuaram com destaque na agenda brasileira, mais em termos econômico-comerciais do que políticos, tendo em vista a objeção ao unilateralismo e ao intervencionismo costumeiramente praticados pelas potências "norte-atlânticas". Ademais, trata-se também de uma política voltada a ampliar a capacidade de barganha e a independência do País.

Aliás, a defesa da multipolaridade e do multilateralismo no sistema internacional foi outro traço distintivo da postura brasileira desde 2003. Desde a sustentação firme dos interesses dos países do Sul com a criação do G20 na Rodada Doha na OMC em 2003, até a não concordância com intervenções externas no Iraque, na Líbia e na Síria, o Brasil, passando pela constante e veemente defesa de uma ONU reformada como foro 


\section{Conjuntura Austral}

ideal e legítimo para solucionar as controvérsias globais, o Brasil manteve como norte de sua atuação internacional a busca por uma maior democratização das relações internacionais.

A despeito da legitimidade intrínseca de suas ações, Brasília sustentava que o impacto de suas ações estaria diretamente conectado com o recrudescimento de seu peso global, e esse, por sua vez, dependeria da construção de uma América do Sul desenvolvida e coesa, voltada para a autonomia do subcontinente. Assim sendo, os países vizinhos e a integração sul-americana passaram a ser a prioridade máxima do governo Lula. O projeto do Mercosul, que assumiu conotações bastante liberais (fruto das políticas dos Governos Collor no Brasil e Menem na Argentina), foi complementado com iniciativas como o FOCEM, com vistas a compensar as desigualdades entre os países-membros, e a ampliação da IIRSA, iniciativa voltada para a integração de infraestrutura dos países sul-americanos. O estabelecimento do Arco das Crises como foco principal de interesse dos EUA após os atentados de 11 de setembro, o fortalecimento das relações sul-sul e a conjuntura regional, marcada pela eleição de governos autonomistas em quase toda a América do Sul, favorecerem os planos de integração da região. Nesse contexto surge o projeto da CASA (Comunidade SulAmericana de Nações) em 2004, que quatro anos mais tarde se concretizou com a UNASUL (União das Nações Sul-Americanas), a partir da assinatura do Tratado de Brasília. Tendo entrado em vigor em 2011, a UNASUL congrega todos os países da América do Sul, e possui características ímpares entre os blocos regionais do subcontinente, em especial a criação do Conselho de Defesa Sul-Americano.

Consideradas em seu conjunto, as prioridades estabelecidas, as táticas empregadas e a ações levadas a cabo pelo Governo Lula tinham como meta um protagonismo mais acentuado do Brasil na arena internacional, o que era considerado condizente com a grandeza e as potencialidades do país. Não é incorreto afirmar que houve sucesso na empreitada. A atuação na $\mathrm{OMC}$, a tentativa de resolução da controvérsia iraniana, a liderança compartilhada na América Sul, o distanciamento crítico das atitudes impositivas e unilaterais dos Estados Unidos, as concertações com os demais membros dos BRICS, entre outros fatores, comprovam uma maior 


\section{Conjuntura Austral}

assertividade da política brasileira, em comparação com aquela vislumbrada nos anos 1980 e, especialmente, 1990.

O discurso de posse da Presidente Dilma Rousseff não dedicou tanto espaço à atuação do Brasil no sistema internacional como havia feito Lula. A América do Sul continuou com considerável destaque, sendo reforçada a conexão entre os destinos do país com o de seus vizinhos, mediante associação do desenvolvimento econômico, social e político doméstico com o do continente (ROUSSEFF, 2011). Uma novidade interessante foi a inclusão da América Central e Caribe entre as regiões a receberem atenção do Brasil, ao lado dos irmãos africanos, dos povos do Oriente Médio e dos países asiáticos. Estados Unidos, União Europeia restaram citados, mas as promessas de "grande atenção" foram reservadas aos países emergentes. A defesa do multilateralismo foi reafirmada como paradigma clássico da política externa brasileira, mas não foi deixada em branco a necessidade de reforma nas instituições de governança global, nomeadamente a ONU e o Conselho de Segurança (ROUSSEFF, 2011).

Assim como no discurso, na condução diária da política, durante os governos Lula e Dilma houve mais continuidade do que mudança em sua atuação externa; ou seja, um autonomismo com diferenças de ênfase. Isso deve-se a inúmeros fatores. Primeiro, seria difícil manter um ativismo diplomático em alto nível todo o tempo, como aquele conduzido pelo chanceler Celso Amorim. Até porque é impossível criar fatos políticos novos permanentemente. Segundo, dada a necessidade de consolidar e dar tempo para o amadurecimento das inúmeras iniciativas criadas no governo anterior. Terceiro, porque o governo Dilma, por perfil político, necessidades domésticas e crise internacional, foi condicionado a redefinir agendas. Mesmo preservando a linha de condução da política externa autonomista, ressalte-se, porém, que o governo cedeu claramente a pressões externas e recuou de algumas agendas, tais como o relacionamento bilateral com o Irã - o que bem se revela no recuo do comércio exterior.

Ainda assim, a liderança brasileira emplacou as candidaturas de Roberto Azevêdo na OMC, a de José Graziano da Silva na Organização Mundial da Agricultura e a de Paulo Vannuchi na Comissão Interamericana de Direitos Humanos. No mesmo sentido, preservou a autonomia e altivez diante dos EUA, denunciando na ONU a 


\section{Conjuntura Austral}

espionagem e se opondo às posições estadunidenses nos conflitos da Síria, Ucrânia e Gaza, por exemplo. Ressalte-se: trata-se, como sugerimos, de preservar autonomia com pragmatismo e sem arroubos antiamericanos.

E o programa de governo da candidata Dilma Rousseff reafirma o papel da política externa no desenvolvimento nacional:

A prioridade à América do Sul, América Latina e Caribe se traduzirá no empenho em fortalecer o MERCOSUL, a UNASUL e a Comunidade dos Países da América Latina e Caribe (CELAC), sem discriminação de ordem ideológica. O Brasil buscará antes de tudo a integração da região, por meio do fomento do comércio e da integração produtiva. (...)

Da mesma forma será dada ênfase a nossas relações com a África, com os países asiáticos - - a China é nosso principal parceiro comercial - e com o mundo árabe. A importância dada aos países do SUL do mundo, que têm expressão concreta nos BRICS, não significa desconsiderar os países desenvolvidos.

Bem ao contrário, é de grande relevância nosso relacionamento com os Estados Unidos, por sua importância econômica, política científica e tecnológica, sem falar no volume de nosso comércio bilateral. Critério semelhante é válido para nossas relações com a União Europeia e com o Japão (PARTIDO DOS TRABALHADORES, 2014).

Como se constata, é possível concluir que mantida em suas grandes linhas a conjuntura global, a política externa brasileira não sofrerá solução de continuidade, em caso de reeleição da Presidenta Dilma Rousseff.

\section{As críticas e os projetos da oposição}

Apresentada a política externa da situação, cabe trazer à baila os projetos das linhas oposicionistas, bem como as críticas que exteriorizaram quanto à condução atual da atuação continental e global do Brasil, pois da contrariedade é possível extrair (no mais das vezes) aquela que será a conduta do país caso uma ou outra candidatura vença as eleições. Cada uma das duas principais correntes de oposição ao Governo Dilma com candidaturas a Presidência já demonstrou seu viés de política externa, por meio de 


\section{Conjuntura Austral}

artigos publicados na mídia ou em seus websites de campanha, entrevistas e declarações. Para fins analíticos, cabe tratar de tais proposições em separado.

\section{Um Retorno ao Alinhamento?}

A candidatura de Aécio Neves possui relação umbilical com o Governo FHC, o que é esperado, tendo em vista as mesmas origem partidária e base político-econômica. Isto é refletido tanto nas críticas feitas à política externa dos Governos Lula e Dilma quanto na visão que guardam da posição do país no concerto mundial de nações. Já a candidatura de Marina Silva, embora oriunda da base governista tal como Eduardo Campos, mantém diretrizes oposicionistas para a inserção internacional do País.

No tocante às críticas, o núcleo da argumentação refere-se, segundo Rubens Barbosa (2008, p. 12) à "ideologização das decisões e à politização das negociações”, se expressando em diversos aspectos. Primeiro, o uso de canais paralelos à relação institucional entre governos através do assessor da Presidência para Assuntos Internacionais, Marco Aurélio Garcia, em seus contatos com partidos de esquerda e movimentos sociais na região. Segundo, a afirmação de uma aliança com a Argentina ao ponto de aceitar suas idiossincrasias, como ficou evidente na criação do Banco do Sul, na aceitação do Mecanismo de Ajuste Competitivo e outras medidas restritivas contrárias ao Tratado de Assunção. Terceiro, uma prática baseada na interlocução por afinidades ideológicas, como atestaria as relações com Evo Morales, Rafael Correa e Hugo Chavez. Quarto, uma política de oferecimento de ajuda financeira e investimentos, como expressos no contexto da nacionalização dos ativos da Petrobrás na Bolívia ou na renegociação do valor da energia elétrica de Itaipu com o Paraguai.

Como consequência, afirma Barbosa (2014), o Mercosul estaria agonizando ao abrir mão da liberalização comercial e admitir "medidas protecionistas sem qualquer punição para os infratores". O resultado, sentencia, teria sido o crescente isolamento do Brasil e do próprio Mercosul nas cadeias produtivas globais, bem como nas negociações de acordos bilaterais e nos mega-acordos de livre comércio. 


\section{Conjuntura Austral}

Segundo Lima \& Duarte (2013, p. 2), o núcleo da crítica à atual política externa seria sua ideologização e sua partidarização, contrária aos verdadeiros interesses nacionais durante os governos de Lula da Silva e Dilma Rousseff, tais como:

"a branda reação brasileira à nacionalização de refinaria da Petrobrás na Bolívia por Evo Morales; a entrada da Venezuela no Mercosul; o afastamento do Paraguai deste mesmo arranjo regional após um processo totalmente irregular de impedimento do então presidente Lugo; a contratação de médicos estrangeiros em especial dos cubanos e, mais recentemente, todo o episódio da "fuga" cinematográfica do senador Roger Molina, asilado na Embaixada brasileira. Com relação ao plano global, perfilam as relações com os países africanos e com o Sul de modo geral, as relações com o Irã e, em especial, a intermediação de Brasil e Turquia no caso do programa nuclear do Irã."

Como consequência do caráter ideológico, seus críticos apontam o equívoco nas escolhas internacionais. Segundo Vera Thorstensen (2014) o Brasil deveria fazer acordos com países grandes, pois não adiante se "casar com pobre" e "atrelar ao Mercosul é a morte, é afundar o Brasil de vez".

Os termos da rejeição à política externa brasileira da última década trazidos à tona vão ao encontro das ideias manifestadas pelo próprio Aécio Neves em sua coluna semanal no jornal Folha de São Paulo. Um dos pontos recorrentes das manifestações do candidato é uma suposta ideologização da política externa brasileira. Aécio criticou a posição do Brasil e dos países do Mercosul quando concederam apoio oficial ao Governo de Nicolás Maduro na Venezuela por ocasião da instabilidade interna, claramente insuflada por forças externas, ocorrida no início de 2014, afirmando que "No lugar de oferecer colaboração institucional para a promoção do diálogo entre as forças políticas em conflito, o Brasil submete sua política externa às conveniências ideológicas, deixando de representar os interesses permanentes do Estado brasileiro para defender o ideário do governo de plantão" (NEVES, 2014). No caso venezuelano em especial, o empenho em espezinhar o governo Dilma, Aécio parece ter esquecido a postura que o próprio FHC tomou ao ser um dos líderes sul-americano que colaborou 


\section{Conjuntura Austral}

para evitar o sucesso do golpe de estado impetrado na Venezuela contra Hugo Chávez em 2002.

Para Aécio, o caminho da ideologização e da "esquerdização" do Governo seria um caminho infrutífero e pernicioso para o Brasil.

A partidarização da política externa tem consequências também na política de comércio exterior. As crises na Venezuela e na Argentina, pela passividade da reação do Itamaraty, estão trazendo prejuízos à credibilidade do governo brasileiro e às empresas nacionais que encontram barreiras para exportar e grandes dificuldades para receber seus pagamentos (NEVES, 2014).

O programa de governo publicado pelo site oficial da campanha de Aécio Neves não é muito claro quanto às eventuais soluções para corrigir rumos da política externa, pois no espaço dedicado às relações exteriores, ele se limita a propagar o fim do isolamento brasileiro, além de uma maior ação diplomática em termos globais, como mudanças climáticas, direitos humanos, comércio exterior, terrorismo, guerra cibernética e ampliação do Conselho de Segurança da ONU (PARTIDO DA SOCIAL DEMOCRACIA DO BRASIL, 2014). Contudo, a despeito da generalidade do seu programa de governo, é plenamente impossível identificar a visão do candidato acerca das linhas mestras de política externa que adotará caso seja eleito Presidente da República.

Entre outros alinhamentos, o Brasil deixou em posição secundária a cooperação com os países desenvolvidos para priorizar as relações com nações emergentes e com os vizinhos no continente, em especial os afinados ideologicamente. Com isso, nossa fatia no comércio internacional vem declinando e nos últimos anos firmamos apenas três acordos comerciais, com países de pouca relevância. Esta política enviesada alija nossas empresas das cadeias globais de produção e, dessa maneira, deixa de gerar aqui empregos de melhor qualidade (NEVES, 2013).

Conforme se observa de forma cristalina, as relações sul-sul almejadas e desenvolvidas pelos Governos Lula e Dilma seriam preteridas em favor da aproximação 


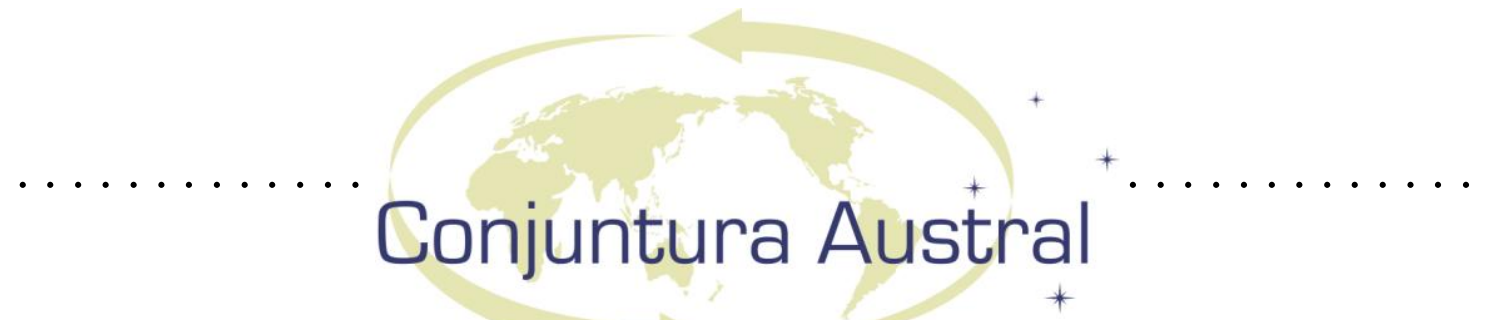

com os países desenvolvidos. A linha argumentativa que mistura isolamento do país e acordos comerciais sinaliza que a inserção internacional de padrão neoliberal e alinhada com as potências centrais (chamadas de desenvolvidas em oposição à falta de desenvolvimento dos demais, inclusive o Brasil) ainda é considerada a mais promissora para o Brasil pelas forças que apoiam Aécio Neves.

No início da campanha, Eduardo Campos direcionou suas críticas em linhas similares àquelas tecidas por Aécio Neves. Apesar de, curiosamente, não ter dedicado atenção ao tema da política externa no Programa de Governo Coligação Unidos Pelo Brasil $^{10}$, as diretrizes de governo, publicada no site da então vice Marina Silva ${ }^{11}$, centrava-se em um pequeno texto com cinco tópicos. Ele se caracteriza por reafirmar posições históricas do Itamaraty (como uma maior equidade das organizações internacionais), por negligenciar todos os temas centrais que caracterizaram os governos Lula-Dilma (BRICS, G20 Comercial, UNASUL, etc.) e por reprisar a tese de que o Brasil tem sido tolerante com os países que violam direitos humanos. Tais posições revelam as contradições entre as propostas de governo e as posições históricas do PSB, notório pelo apoio à tecnologia nuclear, à defesa da soberania nacional, pela crítica ao imperialismo, e pelo apoio a Cuba, entre outros.

Ao assumir a candidatura a frente da chapa, Marina Silva lançou o Plano de Ação para Mudar o Brasil ${ }^{12}$. Nesse documento, no capítulo sobre política externa, inicialmente afirma que não se configurou uma "ascensão definitiva dos emergentes", para depois destacar a importância dos BRICS, do IBAS e da cooperação Sul-Sul na conformação de um mundo multipolar. Destaca ainda a necessidade de o País buscar maior representatividade junto aos organismos internacionais, incluindo o pleito junto ao Conselho de Segurança da ONU. O que difere com ênfase da atual política externa diz respeito à prioridade conferida aos acordos de livre comércio com países centrais e a União Europeia (considerando sugestivo o caminho adotado pelos países da Aliança do Pacífico), ao aprofundamento das relações com os EUA e à defesa de uma diplomacia

\footnotetext{
${ }^{10}$ Ver detalhes no Programa de Governo: http://www.psb40.org.br/imprensa/programa.pdf.

${ }^{11}$ Ver detalhes no site: http://www.marinasilva.org.br/diretrizes_governo/governo/politica-externav2.php.

${ }^{12}$ Ver a íntegra do Programa de Governo: http://marinasilva.org.br/wp-content/uploads/programa.pdf
} 


\section{Conjuntura Austral}

ambiental ativa. Em suma, a plataforma de política externa da candidatura de Marina Silva abarca as iniciativas dos Governos Lula e Dilma, bem como posições caras ao candidato Aécio Neves.

Trata-se, e isso é importante destacar, de uma candidata cuja trajetória e alianças são ambíguas - como atesta a rápida retirada do apoio aos direitos civis dos LGBT e da menção à energia nuclear após a publicação do programa de governo. No campo econômico, há claros sinais da retomada da ortodoxia liberal, com a defesa do Banco Central Independente, o 'tripé econômico' e a redução do papel do Estado na economia - refletindo os interesses do principal financiador, a família Setúbal do Banco Itaú, e do principal conselheiro, o economista neoliberal Eduardo Giannetti. Diante desses fatos, não há garantia de que a parcela do programa de política externa de Marina Silva que espelha as práticas do Governo Dilma seja efetivamente adotada, pois ele vai de encontro com os posicionamentos tradicionalmente defendidos pelos seus principais apoiadores. De todo modo, essa candidatura tem muito a se revelar, pois a presidenciável tem trajetória de projeto pessoal (PT, PV, Rede-PSB), com discurso conservador aferrado a questões religiosas e morais, como é o caso da aversão a direitos civis de minorias e inovações em pesquisas (célula tronco e transgenia). Em suma, a sua defesa da 'nova política', com banqueiros (Setúbal), lideranças políticas tradicionais (Heráclito Forte e Jorge Borhausen) e ícones do conservadorismo (Pastor Silas Malafaia), fazem dessa candidatura ainda um enigma a ser decifrado, mas certamente não um projeto novo de governo.

\section{Uma Nova Concepção de Política Externa?}

A oposição aos governos Lula e Dilma proveniente de grupos autointitulados de esquerda, caso da candidata Luciana Genro, embora inexpressivo do ponto de vista eleitoral, reverbera concepções com livre trânsito em segmentos da academia, como aquelas nucleadas na crítica ao subimperialismo brasileiro. Segundo estas concepções, tais governos instauraram um tripé investimento, financiamento e cooperação internacional (através de órgãos como APEX, BNDES, FIOCRUZ, EMBRAPA, $\mathrm{ABC} / \mathrm{MRE}$, entre outros), garantindo a mesma lógica voraz do capital imposta nos anos 


\section{Conjuntura Austral}

1990 sob o neoliberalismo (FONTES, 2013, p. 108). Para estes, além de servir aos interesses dos EUA de neutralizar as lutas anti-imperialistas na região, o país torna-se extrator de mais valia ao ascender na hierarquia do capitalismo - sem, contudo, melhorar a qualidade de vida da população (LUCE, 2007, p. 50; 2013, p. 132).

O programa de governo divulgado pelo PSOL até julho de 2014 não possui diretrizes muito claras de política externa. No entanto, há referências à atuação brasileira no exterior, sobretudo no tocante às empresas do país e sua relação com o BNDES. Reafirmando argumentos muito próximos aos defensores da tese do subimperialismo brasileiro, a candidatura Luciana Genro defende uma mudança na política de financiamento do BNDES, pois a atual privilegiaria grandes empreiteiras e multinacionais, que possuem capital próprio, ou ao menos acesso a empréstimos internacionais, além de empresas que usam o dinheiro público para aumentar a concentração de renda (PARTIDO SOLIDARIEDADE E LIBERDADE, 2014). Outra manifestação da concepção da candidata acerca da política externa foram dois artigos por ela publicados no site oficial da campanha presidencial, ambos voltados para a criação dos BRICS. No mais recente deles, Luciana Genro critica a utilização que se fará do banco, bem como o papel do Brasil na dinâmica dos BRICS.

A notícia de criação do Banco dos BRICS, que financiaria projetos de desenvolvimento, além da criação de um fundo contra crises financeiras, dá a entender que o governo brasileiro busca mudar a correlação de forças global, tentando reformar o FMI e protestando contra a espionagem dos EUA. Não é bem assim!

A criação deste banco, longe de significar uma alteração no panorama mundial, não passa de mais do mesmo. Seria uma ampliação do atual mecanismo do BNDES, sem participação social, que empresta principalmente a grandes empreiteiras e empresas brasileiras e estrangeiras do ramo primário-exportador, para projetos muitas vezes nocivos ao meio ambiente e às populações afetadas (exemplos: Belo Monte, florestas de eucalipto, mineradoras, etc). Tal esquema pode aprofundar o atual modelo, no qual o Brasil exporta matérias primas para a China industrializá-las (GENRO, 2014b). 


\section{Conjuntura Austral}

Sobre os BRICS em si, Luciana Genro acredita que a iniciativa em si é positiva enquanto utilização do multilateralismo contra a concentração do poder mundial (GENRO, 2014A). Contudo, ela não seria de todo positiva para o Brasil, em função do modo submisso como o Brasil se insere nos BRICS e no sistema internacional. No debate entre as duas linhas tradicionais da política externa brasileira, citadas textualmente pela autora, a sua posição é de questionamento de ambas, pois elas não chegariam a tratar de temas fundamentais como o papel passivo e subordinado do Brasil na divisão internacional do trabalho e as implicações disso para a sua soberania, o que estaria "na contramão de uma verdadeira alternativa de desenvolvimento econômicosocial" (GENRO, 2014A). Apesar de abordar a necessidade de mudanças doméstica na economia e na distribuição de renda e indicar alguns caminhos, o artigo não chega a especificar como um país na posição do Brasil no concerto internacional poderia "enfrentar o poder da finança mundializada e inverter a lógica do modelo produtivo" (GENRO, 2014A). Ou seja, se a crítica da candidatura Aécio reside na ideologização da política externa e no isolamento do Brasil no comércio mundial e dos países industrializados, as objeções de Luciana Genro vão no sentido contrário: o país não possui a autonomia política e ideológica ideal e não questiona os primados do mercado/sistema internacional.

\section{Caminhos e Riscos Possíveis}

Conforme se observa, cada uma das correntes políticas apresentadas possui visão própria da política externa brasileira. Duas delas se aproximam dos paradigmas clássicos de atuação brasileira no sistema internacional, com o Governo representando a linhagem mais autonomista e a oposição encabeçada por Aécio Neves simbolizando a defesa do alinhamento com as potências ocidentais, sobretudo Estados Unidos. A terceira corrente, de Luciana Genro, critica a postura brasileira pela falta de assertividade e pela adesão às normas e instituições globais vigentes, o que a colocaria num espectro inédito em termos de política internacional.

Quanto à candidatura de Luciana Genro, cabe problematizar suas concepções e identificar as limitações que embalam as correntes que julgam criticar pela esquerda o atual governo. Primeiro, negligenciam todos os dados que apontam na direção do 


\section{Conjuntura Austral}

aumento do poder de compra, empregabilidade e redução das desigualdades no Brasil ${ }^{13}$. Desconsideram, pois, aspectos importantes das lutas políticas que buscam fortalecer o desenvolvimento de capacidades produtivas e ações de governo de viés distributivista. Segundo, rejeitam a possibilidade de relações bilaterais ou multilaterais cooperativas, mesmo que os ganhos mútuos tenham assimetrias. Terceiro, supõe, como consequência, que um país periférico (como Bolívia ou Gana) se desenvolveria de forma autocentrada. Ou seja, que poderia se desenvolver sem financiamento externo, como aqueles de longo prazo e baixo custo do BNDES, sem cooperação para o desenvolvimento, como a prestada por centros de excelência como EMBRAPA e FIOCRUZ através da $\mathrm{ABC} / \mathrm{MRE}$, e/ou sem participar de progressos de integração regional com perfil progressista. Quarto, subestimam os constrangimentos e as possibilidades decorrentes das correlações de forças internacionais para países periféricos e/o emergentes; isto é, as dificuldades para se ampliar a autonomia no sistema internacional. Ou seja, não levam em consideração que a dinâmica político-econômica do sistema internacional existe concretamente e, se a sua alteração rumo a um menor desequilíbrio de poder é possível, este é um processo que demanda uma atuação pragmática e cautelosa de uma potência emergente como o Brasil, pois sua implementação em âmbito global é custosa e dotada de vários percalços. Por fim, ressalte-se que os pressupostos da candidatura do PSOL acabam por convergir com as forças conservadoras que fazem ofensivas violentas contra todos os governos populares e desenvolvimentistas - e, portanto, se somam aos interesses dos grupos rentistas pró-americanos no Brasil e na América Latina contrários às relações Sul-Sul.

O atual quadro eleitoral sinaliza para nova polarização entre PT e PSDB, repisando o que tem ocorrido desde as eleições presidenciais de 1994. Portanto, em termos de política externa, a disputa se dá entre a autonomia e o alinhamento; em outras palavras, entre diferentes modelos econômicos e de inserção internacional. De um lado,

\footnotetext{
${ }^{13}$ Ver o relatório Nacional de Acompanhamento dos Objetivos de Desenvolvimento do Milênio (PNUD). Disponível em: http://www.pnud.org.br/Docs/4_RelatorioNacionalAcompanhamentoODM.pdf. Acesso em $08 / 06 / 2014$.
} 


\section{Conjuntura Austral}

Aécio Neves deixou claro que as políticas liberalizantes ${ }^{14}$ retomarão o curso dos anos 1990: contenção do salário mínio, redução do gasto público, retomada das privatizações, diminuição do protagonismo dos Bancos Públicos, autonomia do Banco Central, etc. Tais medidas supostamente colocariam o Brasil nos trilhos do desenvolvimento, aos quais seriam acrescidas novas e promissoras rotas mediante reaproximação do país com os aclamados países desenvolvidos, a tríade Estados Unidos, União Europeia e Japão. As relações Sul-Sul, os BRICS, a integração regional, e outras medidas dotadas de pesadas tintas ideológicas seriam estradas para o precipício do isolamento eterno do Brasil dos grandes centros financeiros mundiais.

A posição sustentada pela candidatura Aécio Neves é descolada das mudanças estruturais do sistema internacional, da conjuntura global, das conquistas recentes da política externa brasileira e até mesmo das posições sustentadas pelo Governo FHC em seu último quarto. A aceitação das diretrizes do Consenso de Washington (1989) a abertura comercial e as privatizações não somente não devolveram dinamismo à economia, como as políticas de ajuste fiscal (Lei de Responsabilidade Fiscal), os planos de demissão voluntária (PDV) e a desregulação financeira acabaram por aumentar a relação dívida/PIB e a vulnerabilidade do País ao cenário internacional instável da década de 1990.

Havia a concepção de que a busca da credibilidade frente aos países centrais teria como contrapartida "reconhecimento político, concessões comerciais e ajuda financeira e tecnológica" (PECEQUILO, 2008, p. 138-141). O que se percebeu foi um progressivo desmonte do projeto nacional a partir da adoção de reformas liberalizantes; da adesão sem contrapartida aos regimes internacionais (Tratado de Não-Proliferação de Armas Nucleares-TNP e Regime de Controle de Tecnologia de Misseis-MTCR); da desmobilização da agenda da diplomacia brasileira no sistema internacional e do refluxo econômico-comercial em outras regiões, especialmente em países periféricos. Durante o

\footnotetext{
${ }^{14}$ Ver entrevista no Estadão de Armínio Fraga, coordenador econômico da campanha do presidenciável do PSDB. Disponível em: http://economia.estadao.com.br/noticias/geral,gasto-publicodeveria-ser-limitado-por-uma-lei-diz-arminio-fraga,181922e. Acesso em 26/06/2014.
} 


\section{Conjuntura Austral}

governo Fernando Henrique a busca de credibilidade e ingresso na globalização implicou mais concessões do que ganhos de espaços.

Em suma, a crise cambial e financeira de 1999, a frustração das elites e do governo diante das expectativas nutridas em relação aos países centrais e a crescente oposição interna aos projetos liberalizantes - incluindo setores conservadores e/ou empresárias que se fiam prejudicados pela aliança com setores financeiros internacionais - fizeram o governo recuar. Segundo André Silva (2009), foi nesse contexto que Fernando Henrique transitou o otimismo liberal para a conceituação de 'globalização assimétrica'. Portanto, a coalizão político-partidária por trás da candidatura Aécio Neves deseja voltar a uma rota da qual ela mesma foi obrigada a se afastar em certa medida há quatorze anos, sendo que os desdobramentos da política e do mercado mundial claramente reforçam que a opção do alinhamento para o Brasil é ainda mais estreita em possibilidades de manobra e resultados esperados do que era nos anos 1990. Por seu turno, a candidatura Dilma Rousseff sustenta a manutenção dos rumos da política externa adotados em seu primeiro mandato, opção que tem sido benéfica para o Brasil, seja no âmbito regional, seja na esfera global.

\section{Considerações finais}

Conforme sugerimos, a eleição deve recolocar, no debate de política externa, os dois modelos e estratégias fundamentais de inserção internacional: autonomismo e alinhamento. Embora se costume colocar que "praticamente tudo que se afasta do relacionamento com os países do Norte é visto como pautado por razões ideológicas, viés partidário", numa lógica binária de soma zero (LIMA \& DUARTE, 2013, p. 2), na prática o que importa não é com quem, mas como estabelecer as relações exteriores.

Não precisamos ir muito longe para perceber que o princípio da autonomia na inserção internacional requer também pragmatismo. Durante o governo Vargas, ocorreu a barganha nacionalista; enquanto no período Geisel, o reconhecimento de Angola e China comunistas e a altivez nas relações com EUA em diversos temas (entre estes, a questão nuclear). Nos governos Lula e Dilma, a ampliação do Mercosul, com a inclusão da Venezuela de Chávez e o estreitamento das relações com a Argentina durante os 


\section{Conjuntura Austral}

governos Kirchner, não impediram a realização de acordos de livre-comércio do bloco com o Egito de Mubarak ou Israel; e a crescente presença no mundo árabe, inclusive com a criação da CASPA (Cúpula América do Sul-Países Árabes) não impediu de estreitar relações com o governo do Irã em meio ao cerco Ocidental.

Trata-se, por óbvio, de opções políticas para a inserção internacional e o desenvolvimento do Brasil. E, nesse sentido, a questão do Mercosul talvez seja a mais sintomática da polarização entre os principais candidatos em disputa. De um lado, há declarações ora exaltadas, como a de Aécio no Fórum da Liberdade de 2014 pugnando o fim do Mercosul ${ }^{15}$, ora matizadas, como as de Rubens Barbosa (2008) se opondo abertamente às políticas de redução das assimetrias e, com efeito, às políticas voltadas a atender demandas dos parceiros regionais. De outro, o relatório que acompanhou a carta de demissão do Alto Representante do Mercosul, Samuel Pinheiro Guimarães, cuja ênfase foi 1) a promoção de políticas de desenvolvimento para enfrentar a desindustrialização, 2) a prioridade sob a integração infraestrutural do bloco, 3) a ampliação da integração com países vizinhos como Suriname, Equador, Bolívia e Guiana, e 4) a expansão das políticas voltadas a redução e assimetrias (como o FOCEM $)^{16}$. A defesa do Mercosul como uma área de integração e desenvolvimento regionais, em oposição ao regionalismo aberto ou à opção por acordos de livre comércio com outros países e blocos defendidos pelos principais candidatos de oposição (Marina e Aécio), vinha sendo um tópico defendido pelo então ministro em diversas oportunidades (GUIMARÃES, 2012; 2014).

Disso conclui-se que o atual pleito coloca em disputa não apenas as políticas da política externa, ou seja, os modelos de inserção internacional, mas o próprio dilema e contradição que vem atravessando a história brasileira e latino-americana como um todo. Isto é, a questão de fundo diz respeito às dificuldades em construir e implementar uma política reformista que avance na direção do desenvolvimento e da autonomia

\footnotetext{
${ }^{15}$ Ver noticio do Valor Econômico "No Rio Grande do Sul, Aécio Neves propõe o fim do Mercosul". Disponível em: http://www.valor.com.br/politica/3509098/no-rio-grande-do-sul-aecio-neves-propoe-ofim-do-mercosul 16 Relatório disponível em: http://www.desenvolvimentistas.com.br/blog/rogeriolessa/files/2012/07/Relat\%C3\%B3rio.pdf. Acesso em: 24/06/2014.
} 


\section{Conjuntura Austral}

nacionais. De Vargas, passando por Jango e Allende, ou Lula, Evo e Kirchner, políticas distributivistas têm encontrado fortes resistências nas elites locais, que por meio de governos autoritários ou liberalizantes buscam reafirmar as tradicionais desigualdades oriundas da formação econômico-política da região. E como o Brasil influencia decisivamente o rumo do subcontinente, não seria demais afirmar que se trata mais do que de um debate de política externa, mas do lugar que a América do Sul irá ocupar no mundo nas próximas décadas. E certamente uma política alinhada, à moda de outros governos (Café Filho, Castelo Branco, Collor e FHC) deverá redefinir o papel do Brasil, em especial o ativismo em organizações como o grupo BRICS, por exemplo.

\section{Referências}

BARBOSA, Rubens. Teremos de ir além do Mercosul. In: Revista Amanhã. 10/04/2014. Disponível em: http://amanha.com.br/index.php?option=com_content\&view=article\&id=6514:teremosde-ir-alem-do-mercosul-\&catid=35:home-2\&Itemid=135

A política externa do Brasil para o Mercosul e o ingresso da Venezuela no Mercosul. In: Interesse Nacional. Abril/junho, 2008, pp. 11-21.

BUENO, Sérgio Ruck. No Rio Grande do Sul, Aécio Neves Propõe o Fim do mercosul. I Valor Econômico.

FARIA, Carlos. O Itamaraty e a Política Externa Brasileira: Do insulamento à busca de coordenação dos atores governamentais e de cooperação com os agentes societários. In: Contexto Internacional. Rio de Janeiro, vol. 34, $\mathrm{n}^{\circ}$ 1, 2012, 311-55.

FONSECA Jr., Gelson. A legitimidade e outras questões internacionais. São Paulo: Paz e Terra, 1998.

GUIMARÃES, Samuel. A União Europeia e o fim do Mercosul. In: Carta Maior. 26/04/2014. Disponível em: http://www.cartamaior.com.br/?/Editoria/Internacional/AUniao-Europeia-e-o-fim-do-Mercosul/6/30799.

. O futuro do Mercosul. In: Austral.vol. 1, nº 1, 2012, pp. 13-22.

LESSA, Antônio Carlos; COUTO, Leandro Freitas; FARIAS, Rogério de Souza.Política externa planejada: os planos plurianuais e a ação internacional do Brasil, 


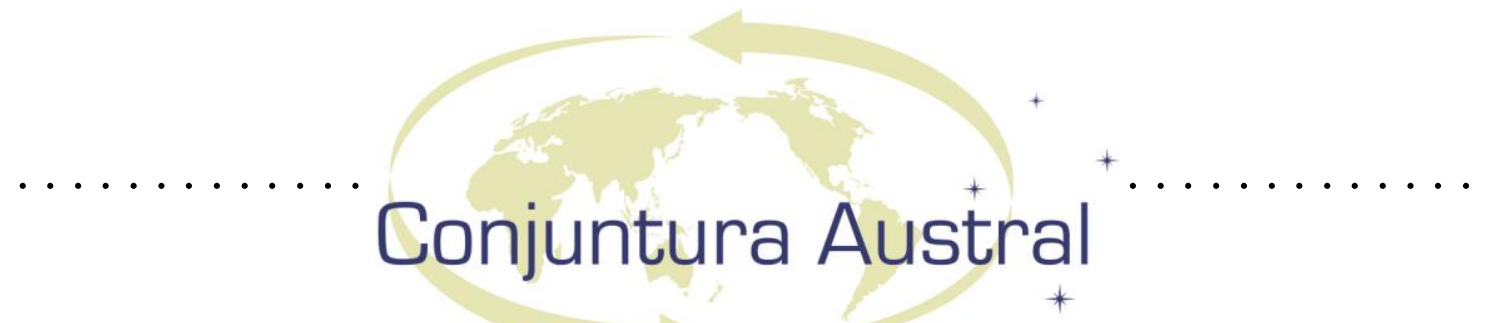

de Cardoso a Lula (1995-2008). In: Revista Brasileira de Política Internacional. Brasília, vol. 52, no 1, 2009, pp. 89-109.

LIMA, Maria; DUARTE, Rubens. Diplomacia presidencial e politização da política externa: uma comparação dos governos FHC e Lula. In: Observatório On-line. vol. 8, $\mathrm{n}^{\mathrm{o}}$ 9, 2013, pp. 1-24.

NEVES, Aécio. (Des)Alinhamento. In Folha de São Paulo, 02/09/2013. http://www1.folha.uol.com.br/colunas/aecioneves/2013/09/1335448-

desalinhamento.shtml. Último acesso em 14 de julho de 2014.

NEVES, Aécio. Diplomacia à Deriva. In Folha de São Paulo, 24/02/2014. Disponível em: http://www1.folha.uol.com.br/colunas/aecioneves/2014/02/1416724-diplomacia-aderiva.shtml. Último acesso em 14 de julho de 2014.

PARTIDO DA SOCIAL DEMOCRACIA NO BRASIL. Propostas: Relações Exteriores e Defesa Nacional. Brasília, 2014. Disponível em http://www.aecioneves.com.br/propostas.php. Último acesso em 23 de julho de 2014.

PARTIDO DOS TRABALHADORES. Mais Mudanças, Mais Futuro: Programa de Governo Dilma Rousseff 2014. Brasília, 2014.

PARTIDO SOCIALISMO E LIBERDADE. Programa. Brasília 2014. Disponível em http://lucianagenro.com.br/programa/. Último acesso em 23 de julho de 2014.

PECEQUILO, Cristina. A política externa do Brasil no século XXI: os eixos combinados de cooperação horizontal e vertical. Revista Brasileira de Política Internacional. Vol. 51, $\mathrm{n}^{\circ}$ 2, 2008., pp. 136.156.

ROUSSEFF, Dilma. Discurso da Presidenta da República, Dilma Rousseff, na Cerimônia de Posse. Brasília: Senado Federal, 2011. Diponível em http://www12.senado.gov.br/noticias/materias/2011/01/01/integra-do-discurso-dapresidente-dilma-rousseff-na-cerimonia-de-posse. Último acesso em 22 de julho de 2014.

SILVA, André. Do otimismo liberal à globalização assimétrica. Curitiba: Juruá, 2009.

SILVA, Luiz Inácio Lula da. Pronunciamento do Presidente da República, Luiz Inácio Lula da Silva, na Sessão Solene de Posse no Congresso Nacional. Brasília: Presidência da República Secretaria de Imprensa e Divulgação, 2003.

THORSTENSE, Vera. Entrevista: "Ficar atrelado ao Mercosul é afundar o Brasil". In: Carta Capital. 19/05/2014. 


\title{
Conjuntura Austral
}

\section{Resumo}

O presente artigo analisa o debate político em torno dos caminhos da política externa diante da eleição para a Presidência em 2014. O argumento central é que a eleição coloca em confronto estratégias distintas de inserção internacional: um voltada ao autonomismo e outra ao alinhamento. Portanto, o que se coloca em disputa não é apenas a política da política externa, mas a própria contradição de um País e de um subcontinente que enfrenta barreiras para romper o seu padrão de desigualdade e dependência.

\section{Palavras-chave}

Política Externa; Brasil; Eleições de 2014.

\begin{abstract}
This article analyzes the political debate on ways of foreign policy before the election to the presidency in 2014. The central argument is that the election confronts distinct international insertion strategies: one dedicated to the autonomist and another alignment. So what stands in dispute is not just the politics of foreign policy, but the very contradiction of a country and a subcontinent facing barriers to break its pattern of inequality and dependence.
\end{abstract}

\section{Keywords}

Foreign Policy; Brazil; Elections 2014.

Artigo recebido em 06 de agosto de 2014. Aprovado em 28 de agosto de 2014. 